\title{
Multistage Multiobjective Optimization for Optimal Energy Management of the Connected Cophase Traction Power System
}

\author{
Saeed Akbari $(i D)$ and Seyed Saeed Fazel $(1 D$ \\ School of Railway Engineering, Iran University of Science and Technology, Tehran, Iran \\ Correspondence should be addressed to Seyed Saeed Fazel; fazel@iust.ac.ir
}

Received 12 October 2021; Revised 17 December 2021; Accepted 23 December 2021; Published 31 January 2022

Academic Editor: Ci Wei Gao

Copyright ( $\odot 2022$ Saeed Akbari and Seyed Saeed Fazel. This is an open access article distributed under the Creative Commons Attribution License, which permits unrestricted use, distribution, and reproduction in any medium, provided the original work is properly cited.

\begin{abstract}
This study presents a multiobjective energy management model for the connected cophase traction power system (CCTPS). Each traction substation (TSS) includes a power flow controller (PFC), energy storage systems (ESS), wind turbine, and PV modules beside a single-phase traction power transformer. Also, in order to exchange the power between the adjacent TSSs, power transfer controllers (PTCs) are used. The proposed energy management model is formulated as a multistage multiobjective optimization problem with a lexicography approach. In the first stage, the cost of purchased energy is minimized. In the second stage, the independence of the CCTPS from the external grid improved. Finally, minimizing the voltage unbalanced ratio (VUR) of CCTPS is considered as the third stage goal. According to the simulation results, utilizing GAMS optimization software, the proposed model will decrease remarkably VUR and dependency of CCTPS without any increase in operation cost.
\end{abstract}

\section{Introduction}

1.1. Background and Motivation. A substantial share of the world's energy consumption (roughly 28\%) is dedicated to the transportation sector [1]. Hence, considering environmental concerns and high-efficiency transportation alternatives have received considerable attention [2, 3]. The development of transportation methods based on rails, especially electric railway systems, is one of the most efficient ways to reduce emissions and energy consumption challenges [4]. However, the expansion of electric railway systems will pose new challenges to the electrical network since they consume large amounts of electricity [5].

Since the advent of electrical railway systems (ERSs), the development of their power supply systems has always been up to date with regards to technological advances [6]. In this respect, the current interest in the reliable-economic operation of ERSs necessitates an active power flow controller in order to manage the transferred power with the upstream grid in the presence of possible elements such as energy storage systems (ESSs) [7]. Regarding this situation, ERS engineers encounter a variety of challenges to develop appropriate feeding schemes, including proposing efficient structures and optimal energy management models [6-8]. Thanks to the development of power systems toward smart grids as well as the remarkable progress of power electronics as a part of the challenges has been mitigated [9]. Also, there are similarities and differences between a cophase traction power system (CCTPS) and a regular power system in the respect of energy management. Apart from inherent power quality problems that have to be considered by CCTPS operators, the variation in the number, speed, and location of locomotives causes rapid changes in demand within a short time period, requiring different scheduling intervals [10-13]. Moreover, railway energy management systems contain different time-based operational modes, including day-ahead operation, minute-ahead operation, and realtime operation that can be categorized into two groups from a managed object viewpoint such as train and traction substation energy management systems [14].

1.2. Literature Review. Through the evolution of ERSs, a great number of feeding schemes have been proposed and 
developed to supply the traction's demand in an economically and stably manner [7]. Nevertheless, the power quality (PQ) issues caused by ERSs, e.g., the low power factor (PF) and the voltage unbalances in the upstream power grid side, affect the stable operation of the external supplier grids [15-18]. PQ problems resulting from phase imbalances are perhaps the main concern for railway engineers [6]. Phase imbalances occur because traction loads are mainly singlephase and fed by three-phase power systems [19]. As a consequence of this issue, a negative sequence current will be caused, and in order to compensate for such power imbalances, an electric power supplier that has a high-enough short-circuit capacity will be required [20]. To solve the PQ issues besides other benefits that are addressed in references [21-23], CCTPS has been employed [24, 25]. CCTPSs can reduce neutral zones by half of the previous systems, eliminate negative sequence currents, and suppress harmonics [26]. It is worth mentioning that neutral zones pose a major barrier to managing energy efficiently and stable operation of the high-speed electric railway systems [27].

As mentioned earlier, ERSs consume a significant amount of energy; consequently, managing the energy flow besides coordinating different facilities in these systems is vital to bring economic-energy savings. In this context, in reference [28], the optimal operation and scheduling of transformers in an ERS are investigated, taking into account their loss of energy. However, the proposed approach is just based on the economic aspect neglecting PQ issues. Akbari et al. and $\mathrm{Li}$ et al. [29-31] proposed optimal operation strategies for several multienergy hub structures deploying regenerative braking energy ( $\mathrm{RBE}$ ) along with renewable energy resources (RERs). Also, providing the cooling, heating, and power demands of ERSs stations have been considered in their models using simple DC power flow equations. However, none of references [28-31] has studied the operational indices associated with the interaction between ERSs and upstream networks, such as voltage unbalanced ratio (VUR) and independence ratio.

Various types of energy storage units with different technologies utilized by ERSs are reviewed by Liu and $\mathrm{Li}$ [32]. Deploying ESSs can enhance the efficiency and performance stability of the ERSs, especially considering the uncertainty in RERs and RBE [32]. Ovalle et al. [33] presented a methodology for sizing ESSs considering a trade-off between energy storage capacity and charging power. Cui et al. [10] presented a hierarchical control strategy aiming to reduce the operation cost and improve the power quality of ERSs by means of a supercapacitor-based ESS. However, managing the ESS and RERs for optimal operation of ERSs has not been addressed simultaneously.

Based on information gap decision theory, Huang et al. [34] proposed an energy management framework for CCTPSs to solve solar power uncertainty. Aguado et al. [35] proposed an optimization model based on the nonlinear programming (NLP) problem for optimal operation of an ERS. Also, RERs, including PV and wind generation, are used to meet the traction load alongside RBE. However, the PQ issues are not considered in their model. Salkuti [36] presented an optimal operating model in which the uncertainty of RER and the total operating cost of the system are considered. However, the mutual impacts between the external grid and ERS and the PQ problems have been neglected. Aiming to reduce the peak power in DC-electrified railway substations, Sumpavakup et al. [37] proposed a strategy for energy storage systems' operation through utilizing RBE. Also, by considering the cost reduction and energy consumption minimization as objective functions, the impact of ESSs on the power peak shaving has been studied. A two-level deterministic energy management model for day-ahead scheduling and minute-ahead operation is presented [38]. Chen et al. [39] presented a deterministic model based on mixed-integer linear programming (MILP) aiming to minimize the operation cost and the error between the day-ahead optimal dispatch results and intraday operating feedbacks. However, neither VUR nor independence ratio has been addressed in their model. An optimal energy management model for CCTPSs is proposed in [40] with an economic saving point of view. Liu et al. [41] presented a multistage robust model in which the uncertainties of PV and traction load have been considered. However, in references [40, 41], the VUR is just taken into account as a constraint, but not as a goal. Table 1 provides a summary of the literature review.

1.3. Contributions and Paper Organization. In this study, a deterministic energy management strategy is proposed for CCTPSs. In the proposed multiobjective model, the traction substations (TSSs) are expected to minimize their operating cost as the main objective of the model. Also, regarding the PQ problems, which could result in penalty charges for ERSs [12], the independence index of CCTPS has been introduced and considered as the second objective. Therefore, unlike references [10,34-41], the proposed model improves the independence of the CCTPS from the external grid because TSSs can exchange power and utilize the dispatchable resources of other TSSs. Moreover, compared to references [35-39], the three-phase VUR is taken into account, and unlike references $[40,41]$, the VUR is considered as the third objective of the proposed model. According to the simulation results, the proposed model will improve simultaneously the VUR and the independence of CCTPS without any increase in operation cost, which is not addressed by previous studies. The main contributions of this study could be listed as follows:

(1) Proposing a novel multistage multiobjective optimization model for CCTPS's operation

(2) Coordinating the RBE utilization, local RERs, and the operation of adjacent traction substations

(3) Minimizing the operation cost of CCTPS and reducing VUR simultaneously without incurring any additional costs

(4) Introducing and improving the independency index of CCTPS

(5) Facilitating the interaction between the upstream power grid and CCTPS through considering VUR and independency index 
TABLE 1: A summary of the literature review.

\begin{tabular}{|c|c|c|c|c|c|c|c|}
\hline \multirow{2}{*}{ Reference } & \multirow{2}{*}{ Aiming to } & \multicolumn{2}{|c|}{$\begin{array}{l}\text { Power } \\
\text { flow }\end{array}$} & \multicolumn{2}{|c|}{ Considering } & \multicolumn{2}{|c|}{ RER } \\
\hline & & $\mathrm{DC}$ & $\mathrm{AC}$ & $\begin{array}{c}\text { PQ } \\
\text { issues }\end{array}$ & $\begin{array}{l}\text { Dependency } \\
\text { index }\end{array}$ & PV & Wind \\
\hline$[34]$ & Minimize the operating cost & & $\checkmark$ & $\checkmark$ & $x$ & $\checkmark$ & $x$ \\
\hline$[35]$ & Minimize the operating cost & & $\checkmark$ & $x$ & $x$ & $\checkmark$ & $\checkmark$ \\
\hline$[36]$ & Minimize the total operating cost & & $\checkmark$ & $x$ & $x$ & $\checkmark$ & $\checkmark$ \\
\hline$[37]$ & Reduce the peak power demand of TSS & $\checkmark$ & & $x$ & $x$ & $x$ & $x$ \\
\hline$[38]$ & Minimize cost and energy consumption & $\checkmark$ & & $x$ & $x$ & $x$ & $x$ \\
\hline [39] & Minimize the operating costs and operation deviation & $\checkmark$ & & $x$ & $x$ & $\checkmark$ & $\checkmark$ \\
\hline [40] & Minimize the daily operating cost & & $\sqrt{ }$ & $\sqrt{ }$ & $x$ & $\sqrt{ }$ & $x$ \\
\hline [41] & Minimize the operating cost & & $\checkmark$ & $\checkmark$ & $x$ & $\checkmark$ & $x$ \\
\hline This study & $\begin{array}{c}\text { Minimize the operating cost and voltage unbalances ratio and improve the } \\
\text { independence from the external grid }\end{array}$ & & $\checkmark$ & $\checkmark$ & $\checkmark$ & $\checkmark$ & $\checkmark$ \\
\hline
\end{tabular}

The rest of this study is organized as follows. In Section 2, the CCTPS structure is introduced, and the mathematical model of the system is presented. The methodology of solving the multistage optimization problem is expressed in Section 3. Section 4 represents simulation results, and Section 5 contains a summarized conclusion.

\section{System Modeling}

Figure 1 shows the architecture of cophase TSSs and the feeding scheme of presumed CCTPS. In each TSS, a singlephase transformer worked along with a power flow controller to supply traction load. Through this feeding scheme, the PQ problems, including PF, VUR, and the negative sequence current in the upstream grid side, can be alleviated $[40,41]$. Besides, PV modules, wind turbines, and ESSs are employed by TSSs. The adjacent TSSs can exchange power utilizing AC-DC-AC power conversion units as power transfer controllers (PTCs). In the following, the mathematical model of the mentioned elements is presented beside the objective functions of the proposed energy management strategy.

2.1. Energy Storage System. The dynamic model of ESSs is used in the proposed model. To ensure the proper performance of ESSs, some technical constraints must be satisfied, which are translated to a set of mathematical constraints, consisting of relationships (1)-(6). Also, $i$ and $t$ denote the indices of TSS and time, respectively.

$$
\begin{gathered}
E_{i, t+1}^{b}=E_{i, t}^{b}\left(1-\delta_{i}^{b}\right)+\left(P_{i, t}^{b, c} \cdot \eta_{i}^{b, c}-\frac{P_{i, t}^{b, d}}{\eta_{i}^{b, d}}\right) \cdot \Delta t, \\
i \in I, t \in T, \\
0 \leq P_{i, t}^{b, c} \leq P_{i}^{\max , c} \cdot u_{i, t}^{b, c}, \quad i \in I, t \in T, \\
0 \leq P_{i, t}^{b, d} \leq P_{i}^{\max , d} \cdot u_{i, t}^{b, d}, \quad i \in I, t \in T, \\
u_{i, t}^{b, d}+u_{i, t}^{b, d} \leq 1, \quad i \in I, t \in T,
\end{gathered}
$$

$$
\begin{aligned}
E_{i}^{\min } \leq E_{i, t}^{b} \leq E_{i}^{\max }, \quad i \in I, t \in T, \\
E_{i, \text { initial }}^{b}=E_{i, \text { end }}^{b}, \quad i \in I,
\end{aligned}
$$

where $E_{i, t}^{b}$ denotes the state of energy (SOE) of ESS in TSS $i$ at time interval $t$ [42]. The constraints (2) and (3) prevent the charging and discharging power of ESS to exceed their maximum capacity rates. To avoid simultaneously charging or discharging ESS, constraint (4) checks the ESS charging and discharging mode at each time interval through two binary variables represented $u_{i, t}^{b, c}$ and $u_{i, t}^{b, d}$ [43]. The constraint (5) limits the SOE to be in the narrow of the maximum and minimum allowed values. In addition, by constraint (6), the initial and final conditions of ESS are met [44].

2.2. PV Module. Solar irradiance and ambient temperature, as the main external factors, as well as the specification of a PV module determine its power output. The relationship between these parameters can be expressed by (7) $[45,46]$. Also, the specifications of PV modules according to reference [47] are used.

$$
P_{i, t}^{p v}=\eta_{i}^{p v} \cdot S_{i}^{p v} \cdot I_{i, t}^{p v}\left(1-0.005\left(T_{i, t}^{a m}-25\right)\right) .
$$

2.3. Wind Turbine. The wind turbine output is calculated by the following equation widely used in studies [48].

$$
P_{i, t}^{W}= \begin{cases}0, & V_{i, t} \leq V_{i}^{c i}, \\ P_{i}^{W, N o m}\left(A_{i} V_{i, t}^{2}+B_{i} V_{i, t}+C_{i}\right), & V_{i}^{c i} \leq V_{i, t} \leq V_{i}^{r}, \\ P_{i}^{W, N o m}, & V_{i}^{r} \leq V_{i, t} \leq V_{i}^{c o}, \\ 0, & V_{i}^{c o} \leq V_{i, t} .\end{cases}
$$

2.4. Power Transfer Controller. Inequality (9) prevents the transferred power between TSS $i$ and $j$ to achieve an amount higher than PTC's capacity. The state of transferring power is modeled by the binary variable $a_{i, j}^{P T C}$ as a parameter in the 


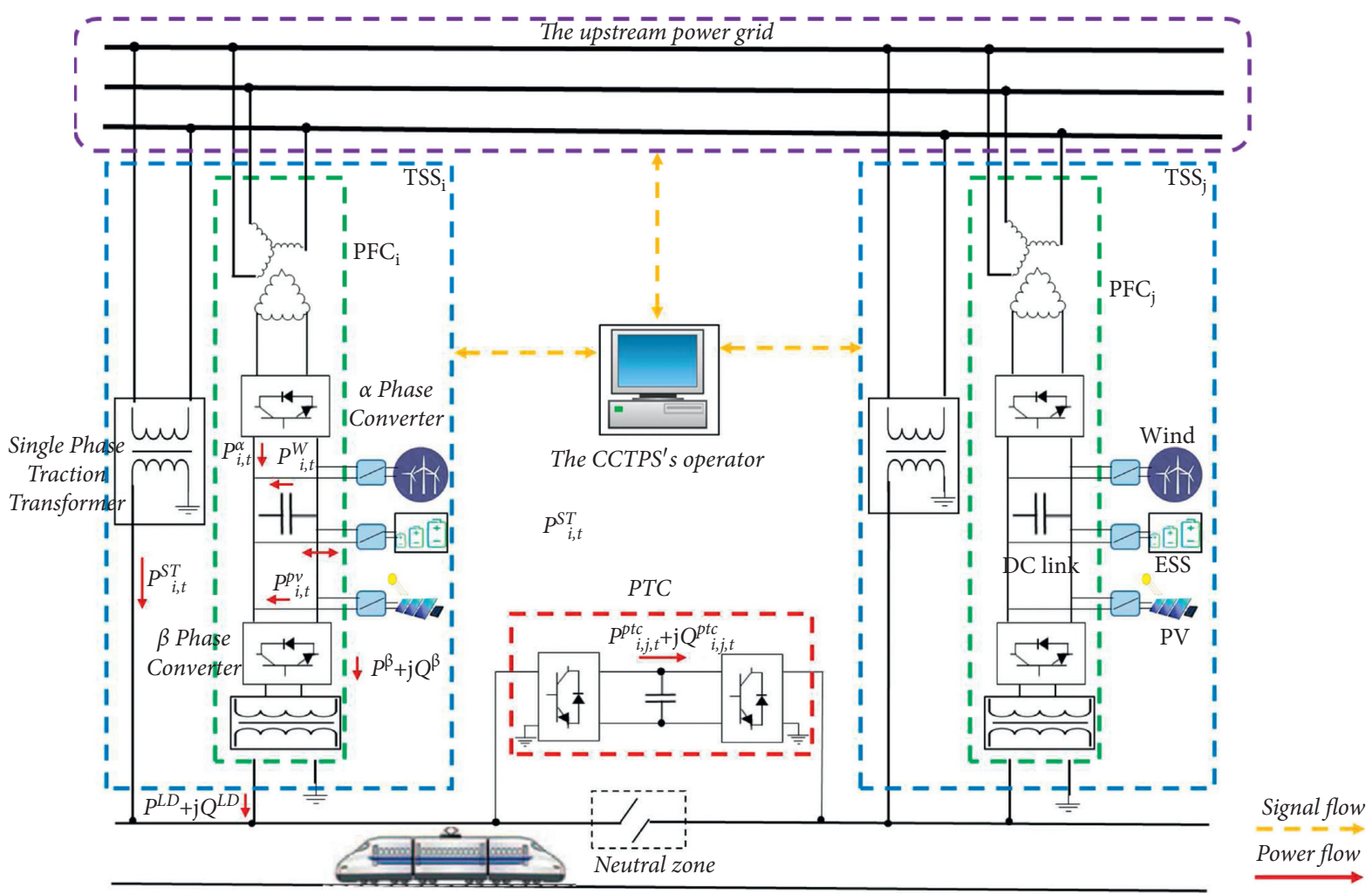

FIGURE 1: The architecture of the connected cophase traction system.

optimization problem. The power balance between two adjusts TSSs is guaranteed by

$$
\begin{array}{r}
\left(P_{i, j, t}^{P T C}\right)^{2}+\left(Q_{i, j, t}^{P T C}\right)^{2} \leq\left(S_{i, j}^{P T C}\right)^{2} \cdot a_{i, j}^{P T C}, \\
i, j \in I, i \neq j, t \in T, \\
P_{i, j, t}^{P T C}=-P_{j, i, t}^{P T C}, \quad i, j \in I, i \neq j, t \in T, \\
Q_{i, j, t}^{P T C}=-Q_{j, i, t}^{P T C}, \quad i, j \in I, i \neq j, t \in T .
\end{array}
$$

2.5. Power Flow Controller. The PFC is a back-to-back converter that connects the railway feeding grid to the upstream grid through two convertors named $\alpha$ and $\beta$-phase convertors. The PV and ESS adjoin to the feeding scheme by the DC-link between $\alpha$ and $\beta$-phase converters. The transmitted power through the convertors is limited by

$$
\begin{array}{r}
-S_{i}^{\alpha} \leq P_{i, t}^{\alpha} \leq S_{i}^{\alpha}, \quad i \in I, t \in T, \\
\left(P_{i, t}^{\beta}\right)^{2}+\left(Q_{i, t}^{\beta}\right)^{2} \leq\left(S_{i}^{\beta}\right)^{2}, \quad i \in I, t \in T .
\end{array}
$$

2.6. Energy Balance. The active and reactive power flow must be in balance at each time interval. The balance of active power in each node is expressed by (14), (15), and (17), as well as that for the reactive power in (16).

$$
\begin{aligned}
& P_{i, t}^{G, \text { buy }}=P_{i, t}^{G, \text { sell }}+P_{i, t}^{S T}+P_{i, t}^{\alpha}, \quad i \in I, t \in T . \\
& P_{i, t}^{\alpha}-P_{i, t}^{\beta}+P_{i, t}^{p v}=P_{i, t}^{b, c}-P_{i, t}^{b, d}, \quad i \in I, t \in T, \\
& Q_{i, t}^{\beta}=Q_{i, t}^{L}-Q_{i, t}^{R B E}+Q_{i, j, t}^{P T C}, \quad i, j \in I, i \neq j, t \in T, \\
& P_{i, t}^{S T}+P_{i, t}^{\beta}+P_{i, t}^{R B E}=P_{i, t}^{L}+P_{i, j, t}^{P T C}, \quad i, j \in I, i \neq j, t \in T .
\end{aligned}
$$

As stated in (14), the power exchanging between TSS $i$ $\left(P_{i, t}^{G, \text { buy }}, P_{i, t}^{G \text { sell }}\right)$ and the upstream grid is carried out through the $\alpha$-phase convertor and the single-phase transformer $\left(P_{i, t}^{S T}\right)$. Constraint $(15)$ illustrates the power balance on the DC-link node. The $\beta$-phase converter controls the reactive power balance through constraint (16) and supplies the traction loads along with the single-phase transformer, employing constraint (17). Also, $P_{i, t}^{L}$ and $Q_{i, t}^{L}$ are the active and reactive power traction loads, as well as $P_{i, t}^{R B E}$ and $Q_{i, t}^{R B E}$ for regenerative braking.

2.7. Objective Functions. As stated, CCTPS is seeking to minimize its operation cost in the form of energy cost exchanged with the upstream grid, which is expressed as

$$
\operatorname{Min} \Phi_{1}=\operatorname{Min} \cdot \sum_{i \in I} \sum_{t \in T}\left(P_{i, t}^{G, \text { buy }} \cdot \rho_{t}^{\text {buy }}-P_{i, t}^{G \text {,sell }} \cdot \rho_{t}^{\text {sell }}\right) \cdot \Delta t
$$

where $\Phi_{1}$ is the cost of exchanging energy between CCTPS and the upstream grid, $\rho_{t}^{\text {buy }}$ and $\rho_{t}^{\text {sell }}$ denote to the purchasing 
and selling price of electricity, and $P_{i, t}^{g, \text { buy }}$ and $P_{i, t}^{g, \text { sell }}$ express the purchased and sold power from or to the upstream grid by TSS $i$ at time interval $t$. As a result, their adjustment can determine how much power is transferred to the external grid.

Since TSSs are connected, they can share their facilities, including renewable energy power generation and the emerged RBE. As a result, the amount of excess energy in each TSS can provide the demand of the other substations instead of selling it to the external grid. Consequently, in the second stage of optimization, by minimizing the total purchased power from the upstream grid, the operation of the facilities will be rescheduled in the way that TSSs have more exchange with each other instead of with the external grid. In the following equation, $\Phi_{2}$ is the second goal, which shows the total purchased power from the upstream grid, and is considered as the index of dependency on the external grid.

$$
\operatorname{Min} \Phi_{2}=\operatorname{Min} \sum_{t \in T} P_{i, t}^{g, \text { buy }}
$$

Regarding $\mathrm{PQ}$ issues, the third objective function is allocated to the total three-phase VUR. Based on Chen et al. study [49], the three-phase VUR in the upstream grid side can be calculated as

$$
\begin{aligned}
\varepsilon_{i, t}^{U} & =\sqrt{3} \frac{U_{s}\left|I_{i, t}^{-}\right|}{S_{\text {cap }}}, \quad i \in I, t \in T, \\
\operatorname{Min} \Phi_{3} & =\operatorname{Min} \sum_{i \in I} \sum_{t \in T} \varepsilon_{i, t}^{U},
\end{aligned}
$$

where $\varepsilon_{i, t}^{U}$ expresses the three-phase voltage unbalanced ratio caused by TSS $i . I_{i, t}^{-}, U_{s}$, and $S_{\text {cap }}$ are the negative sequence current in the grid side, the nominal voltage of the grid, and the short-circuit capacity, respectively. In addition, to keep $\varepsilon_{i, t}^{U}$ lower than the maximum allowed amount, the following equation is employed.

$$
\varepsilon_{i, t}^{U} \leq \varepsilon_{i}^{\max , U}, \quad i \in I, t \in T .
$$

Also, the negative sequence current is determined based on the feeding scheme, such as the connection type of the matching transformer at the high voltage side of the CCTPS, which can be calculated as [23]

$$
\left|I_{i . t}^{(-)}\right|=\left|\frac{K^{T S}}{U^{T S}} \cdot P_{i, t}^{T S}-\frac{K^{\alpha}}{U^{\alpha}} \cdot P_{i, t}^{\alpha}\right|,
$$

where $K^{T S}$ and $K^{\alpha}$ are the coefficients relevant to the architecture of the implemented feeding scheme and the specification of PFC, according to reference [23] containing the modeling procedure and the associated mathematical relationships.

\section{The Multistage Multiobjective Optimization Solving Method}

There is a variety of solving methods for multiobjective optimization problems [50]. In this study, with regards to the priorities of objective functions for the CCTPS's operator, a lexicography approach is used to establish the proposed model in a multistage way. Defining 3 stages, the optimal results of the stages with higher priority are considered as constraints in the optimization process of lower stages. For the sake of clarity, $\Phi_{1}$ is considered as the first objective function with the highest priority for the CCTPS's operator. The second objective or $\Phi_{2}$ is minimized while the optimal result of $\Phi_{1}$, which is obtained from the first stage, has been integrated into the second stage of the optimization problem. The same procedure for stage three is considered. Figure 2 shows the flowchart of the solving presses. Also, according to the linearization techniques for an absolute value function, equation (23) can be replaced by $(24)-(27)$.

$$
\begin{aligned}
\left|\frac{K^{T S}}{U^{T S}} \cdot P_{i, t}^{T S}-\frac{K^{\alpha}}{U^{\alpha}} \cdot P_{i, t}^{\alpha}\right| & =X_{i, t}-Y_{i, t}, \quad i \in I, t \in T, \\
\frac{K^{T S}}{U^{T S}} \cdot P_{i, t}^{T S}-\frac{K^{\alpha}}{U^{\alpha}} \cdot P_{i, t}^{\alpha} & =X_{i, t}-Y_{i, t}, \quad i \in I, t \in T \\
X_{i, t} & \leq M \cdot u_{i, t}^{\text {linear }}, \quad i \in I, t \in T, \\
Y_{i, t} & \leq M \cdot\left(1-u_{i, t}^{\text {linear }}\right), \quad i \in I, t \in T
\end{aligned}
$$

where $M$ is a big number, and $X_{i, t}$ and $Y_{i, t}$ are the two auxiliary positive variables. In addition, according to (23), the negative sequence currents can be canceled through the operation of both single-phase transformer and PFC at the same time. Therefore, their stable operation should be guaranteed in order to apply the proposed energy management strategy. Moreover, according to (15), since the energy flow in PFC significantly depends on the production of renewable energies, their power generation should be forecasted accurately. However, ESS, as a dispatchable resource, can compensate for a part of upcoming prediction errors.

\section{Simulation Results}

The proposed energy management model, as a mixed-integer quadratically constrained programming (MIQCP) problem, is simulated in GAMS software and solved by the CPLEX solver on an Intel Core i5 $2.53 \mathrm{GHz}, 6.0 \mathrm{~GB}$ RAM computer [51].

4.1. Input Data. In order to evaluate the effectiveness of the proposed model, 3 TSSs are considered with the same feeding scheme as shown in Figure 1, which are connected through PTCs. Technical parameters of each TSS's devices are given in Table 2. Figure 3 shows $\mathrm{PV}$ and wind power generation in a day. Real-time pricing (RTP) scheme is used for the electricity tariff according to Figure 4. Also, the selling price is assumed to equal the purchasing cost. 




FIgURE 2: The flowchart of the optimization of the proposed energy management model.

Table 2: The technical specification of the employed devices and facilities.

\begin{tabular}{lccc}
\hline Parameter & TSS $_{1}$ & TSS $_{2}$ & TSS $_{3}$ \\
\hline$P_{i}^{\max , c}(\mathrm{~kW})$ & 500 & 400 & 600 \\
$P_{i}^{\max , d}(\mathrm{~kW})$ & 500 & 400 & 600 \\
$E_{i}^{\max }(\mathrm{kWh})$ & 1000 & 800 & 12000 \\
$E_{i}^{\min }(\mathrm{kWh})$ & 200 & 160 & 240 \\
$K^{T S}$ & $1 / \sqrt{3}$ & $1 / \sqrt{3}$ & $1 / \sqrt{3}$ \\
$K^{\alpha}$ & $1 / 3$ & $1 / 3$ & $1 / 3$ \\
$\varepsilon_{i}^{\max , U}(\%)$ & 2 & 2 & 2 \\
$P_{i}^{W, N o m}(\mathrm{~kW})$ & 750 & 0 & 500 \\
$V_{i}^{c i}(\mathrm{~m} / \mathrm{s})$ & 2.5 & 2.5 & 2.5 \\
$V_{i}^{r}(\mathrm{~m} / \mathrm{s})$ & 14 & 14 & 14 \\
$V_{i}^{c o}(\mathrm{~m} / \mathrm{s})$ & 25 & 25 & 25 \\
$S_{i}^{p v}\left(\mathrm{~m}^{2}\right)$ & 1400 & 1700 & 2500 \\
$\eta_{i}^{p v}(\%)$ & 15.7 & 15.7 & 15.7 \\
\hline
\end{tabular}

\section{Simulation Results and Discussion}

Table 3 provides the optimization problem results in each stage, including the daily operation cost, the index of dependency, and the total three-phase VUR. For the sake of clarity, it should be mentioned that the variation columns illustrate the alterations between the results of the first stage with those of other stages. Comparing the results of the first and second stages, the purchasing energy from the upstream grid is decreased by about $8.36 \mathrm{MWh}$ or $12 \%$. In the second stage, most of the harvested energy, including the RBE and renewable resources' output, is used to supply CCTPS 




(a)

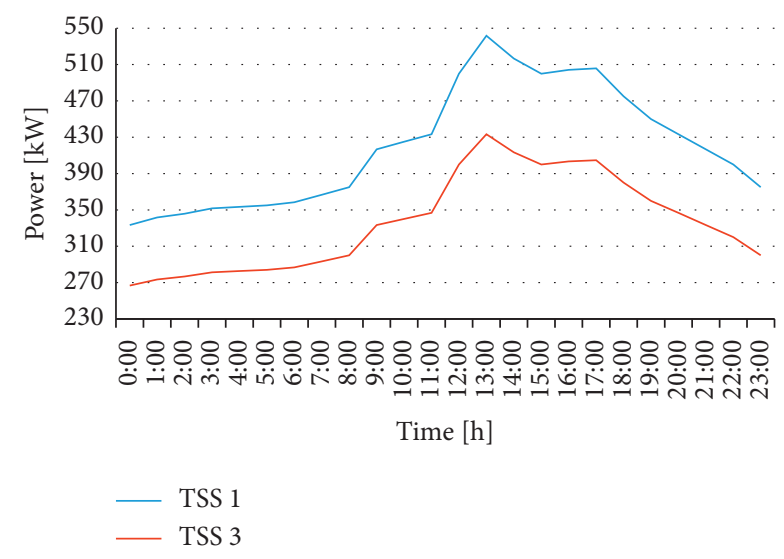

(b)

FIgURe 3: The renewable power generation profiles during the day. (a) The PV power generation profile. (b) The wind generation power profile.

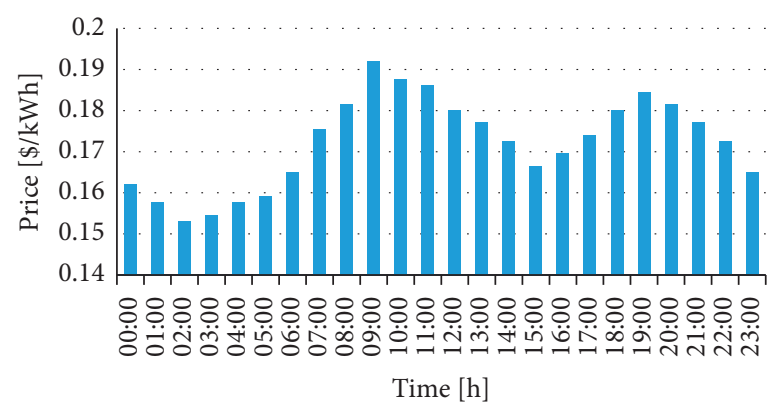

FIGURE 4: The electricity price during the day.

TABle 3: Optimization results.

\begin{tabular}{|c|c|c|c|c|c|c|}
\hline \multirow{2}{*}{ Optimization stage } & \multirow{2}{*}{ Entity } & \multicolumn{2}{|c|}{$\Phi_{1}$} & \multicolumn{2}{|c|}{$\Phi_{2}$} & \multirow{2}{*}{$\begin{array}{c}\Phi_{3} \\
\text { Amount (\%) }\end{array}$} \\
\hline & & Amount (\$) & Variation (\%) & Amount (MWh) & Variation (\%) & \\
\hline \multirow{4}{*}{ The first stage } & TSS 1 & 2032.2 & - & 21.2 & - & 5.56 \\
\hline & TSS 2 & 3654.6 & - & 24.4 & - & 5.6 \\
\hline & TSS 3 & 2194.5 & - & 21.8 & - & 5.31 \\
\hline & CCTPS & 7881.3 & - & 67.4 & - & 16.47 \\
\hline \multirow{4}{*}{ The second stage } & TSS 1 & 2447.6 & 20 & 19.0 & -10 & 5.139 \\
\hline & TSS 2 & 2847.3 & -22 & 20.0 & -18 & 5.34 \\
\hline & TSS 3 & 2586.4 & 18 & 20.0 & -8 & 5.19 \\
\hline & CCTPS & 7881.3 & 0 & 59.0 & -12 & 15.67 \\
\hline \multirow{4}{*}{ The third stage } & TSS 1 & 2297.1 & 13 & 18.9 & -11 & $4.3 \mathrm{e}-4$ \\
\hline & TSS 2 & 3072.4 & -16 & 20.1 & -18 & $3.7 \mathrm{e}-8$ \\
\hline & TSS 3 & 2511.8 & 14 & 20.1 & -8 & $3.8 \mathrm{e}-8$ \\
\hline & CCTPS & 7881.3 & 0 & 59.0 & -12 & $1.3 \mathrm{e}-4$ \\
\hline
\end{tabular}

demands instead of selling it to the upstream grid. Comparing the results of the first and third stages, the total threephase VUR remarkably improved without additional cost in scheduling manner, beside the independency of CCTPS is improved by $12 \%$. However, a well-designed control system is required to realize the optimal scheduled results. Comparing the results of the second and third stages, the total three-phase VUR reduced about $15 \%$ without increasing the daily operation cost and the purchased energy from the upstream grid.

The proposed energy management strategy is compared to other similar studies [35-41] in order to demonstrate its advantages. Although the uncertainties of RERs have been considered $[35,36]$, neither the interactions between ERSs and upstream grids nor the VUR have been considered. In addition, the comparison test results infer that under stage 1 


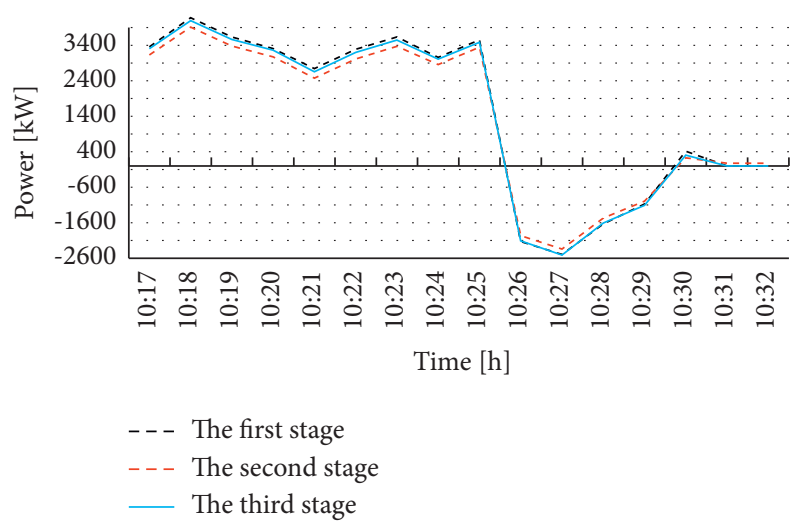

FIGURE 5: The transferred power of TSS 3 with the upstream grid at different stages. (a) Transferred power between TSSs 2 and 1. (b) Transferred power between TSSs 2 and 3 .

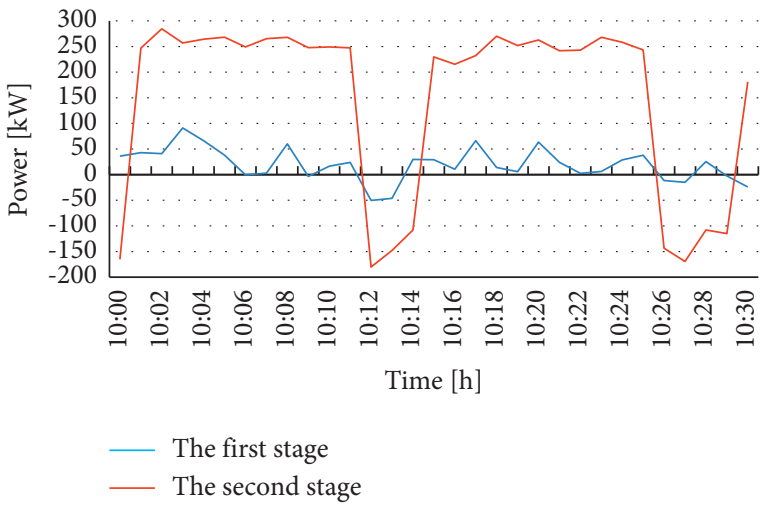

(a)

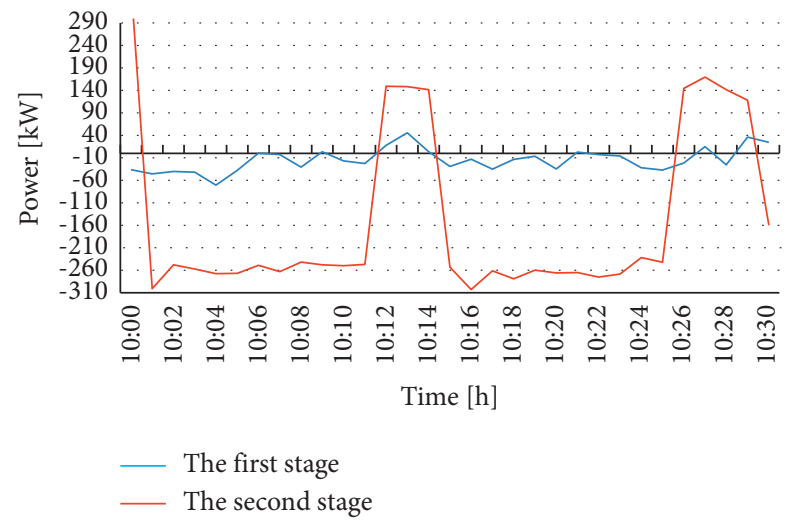

(b)

FIGURE 6: The transferred power between TSSs.

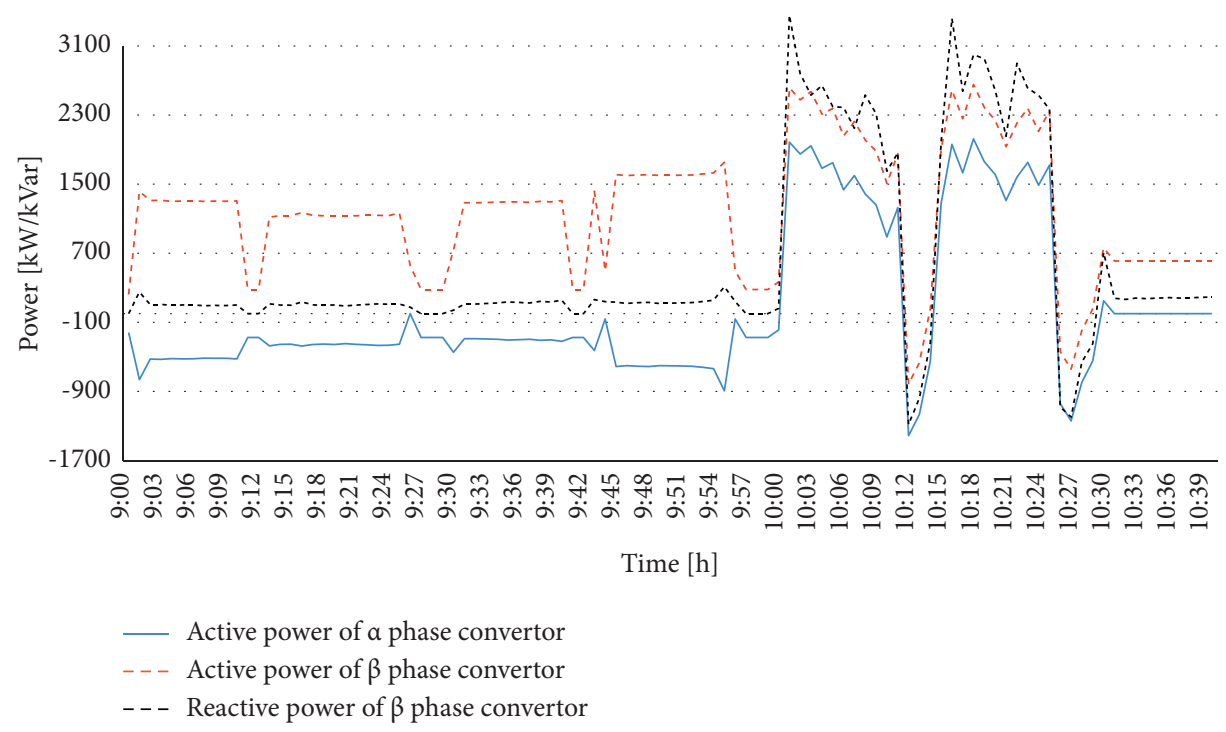

(a)

Figure 7: Continued. 


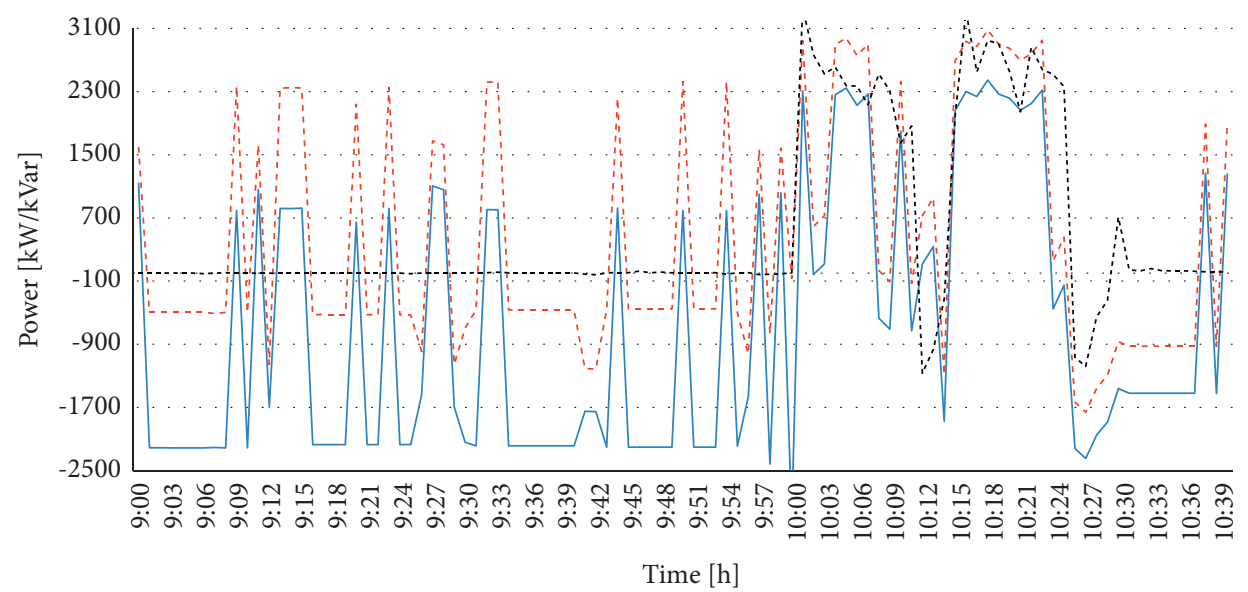

- Active power of $\alpha$ phase convertor

- - Active power of $\beta$ phase convertor

- - - Reactive power of $\beta$ phase convertor

(b)

Figure 7: The optimal scheduled power for PFC convertors. (a) The optimal schedule in stage 3. (b) The optimal schedule in stage 2.

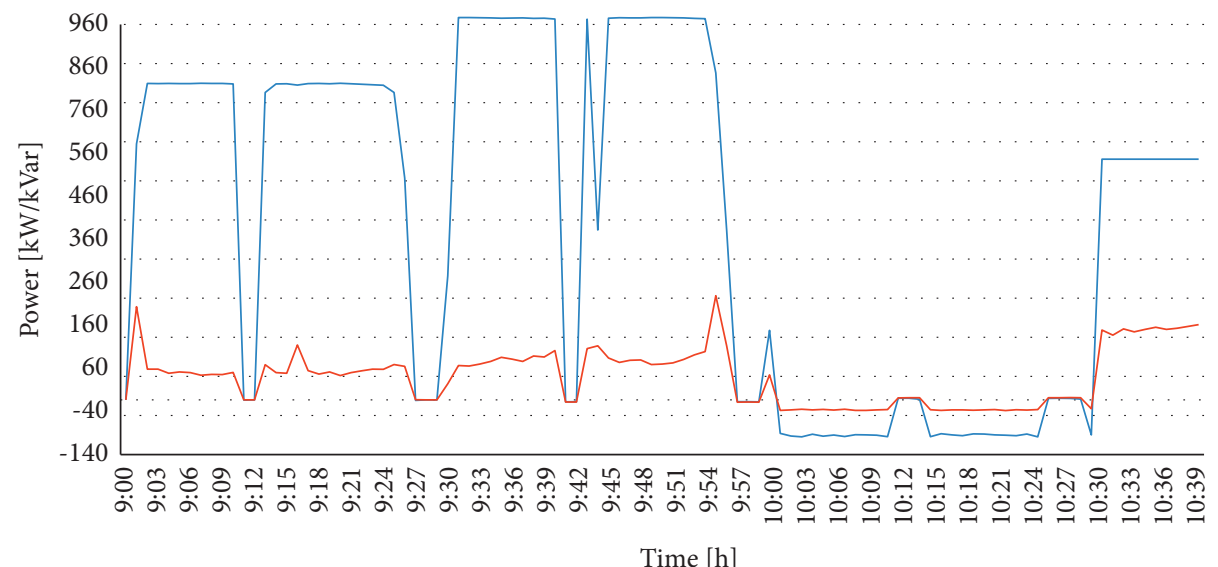

Time $[\mathrm{h}]$

- Active power

Reactive power

Figure 8: The transferred power between TSSs 3 and 2.

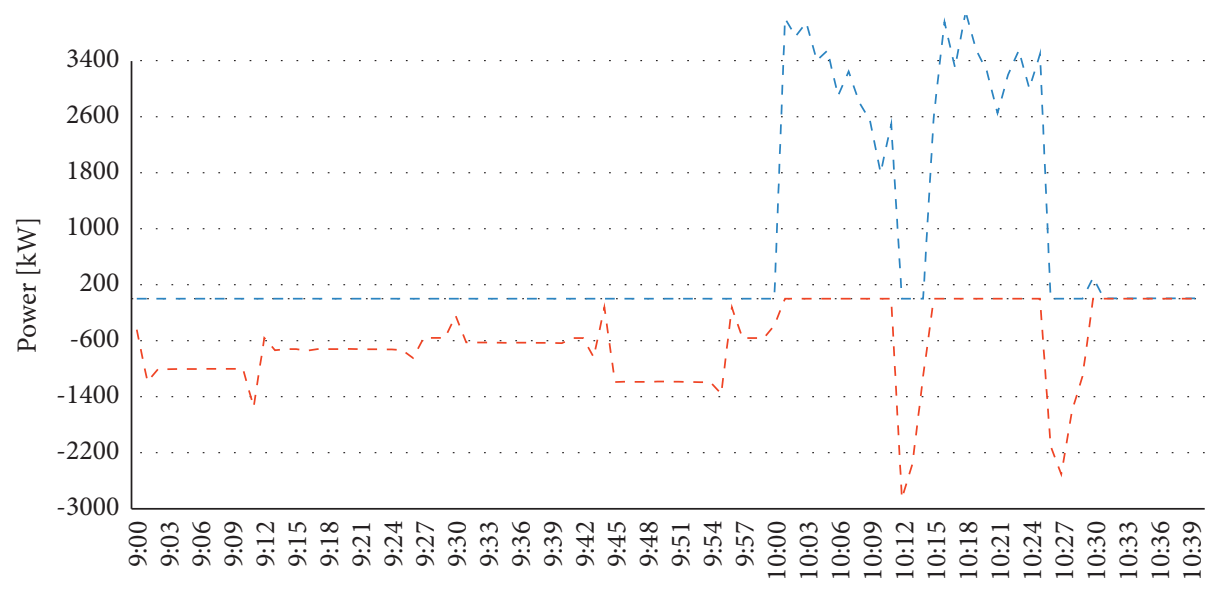

Time $[\mathrm{h}]$

- - Purchased power from the grid

- - - Sold power to the grid

Figure 9: The optimal scheduled exchanging power with the upstream grid. 
TSS 1

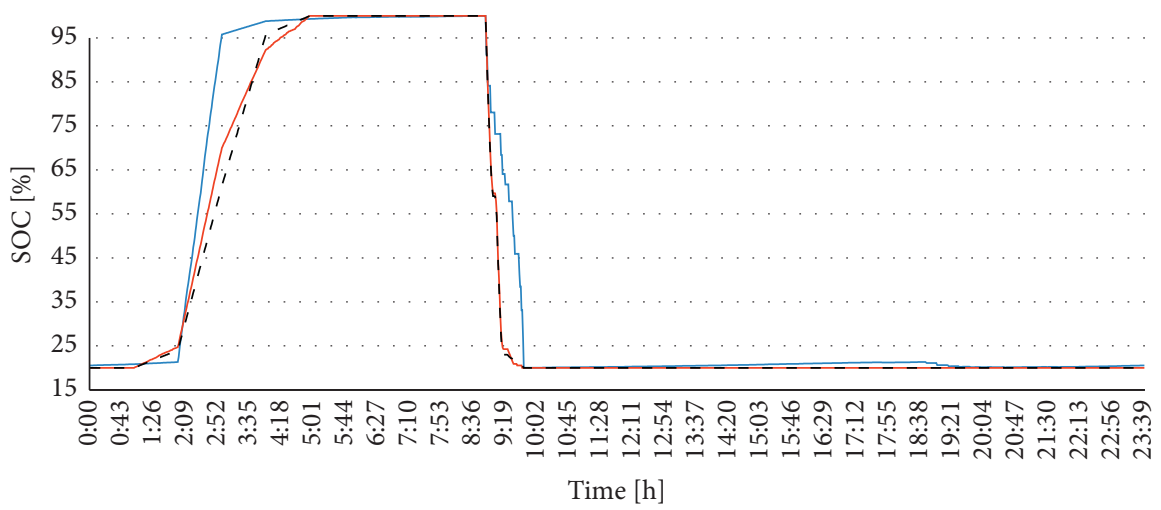

_ The first stage

- The second stage

- - - The third stage

TSS 2

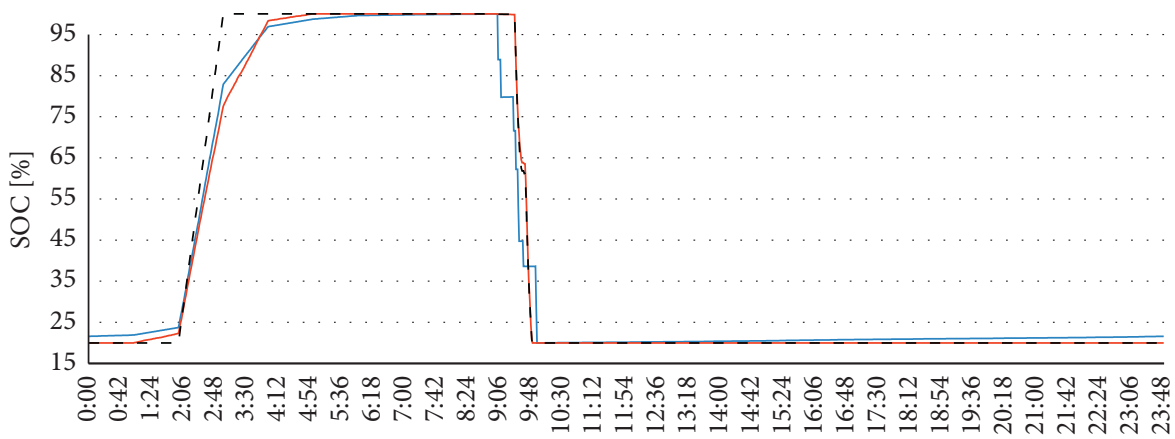

Time $[\mathrm{h}]$

- The first stage

— The second stage

- - - The third stage

TSS 3

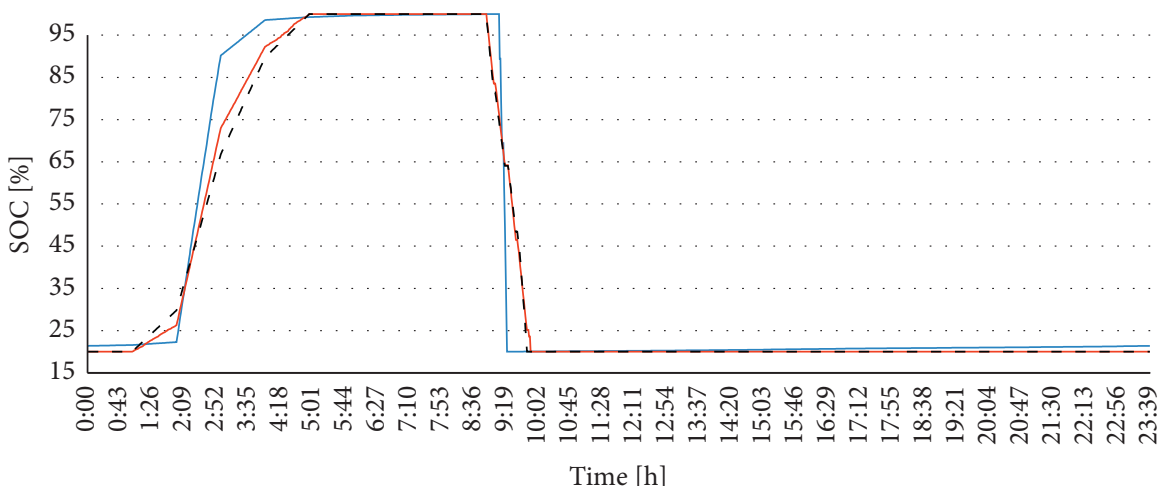

- The first stage

The second stage

- - The third stage

FIgURE 10: The SOC of ESSs in TSSs during the day.

of the proposed model, considering just operational costs like the approach of references [38-41], about $12 \%$ or $8 \mathrm{MWh}$ more energy should be purchased from the external grid. Whereas, through the opportunity that the interconnection of TSSs will bring by sharing their facilities, the amount of purchased energy could be reduced by deploying the approach of stage 2 of the proposed model. Moreover, although by reducing the exchanged power with 
the external grid, the VUR will decrease consequently (about $1 \%$, by observing the results of stages 1 and 2 ), and the significant difference between the results of stage 1, the same approach as references [38-41], and stage 3 highlights the success of the proposed model in order to reduce VUR which is about $16 \%$.

The decrease in exchanged power with the upstream grid in the second stage, including less purchased or sold power, is the first result that claims attention in Figure 5 that can improve the peak-to-valley ratio of the power profile through this stage. Additionally, as a result, the transferred power between TSSs will increase, and they support each other in order to provide their demand. The transferred power between TSSs is shown in Figure 6 .

Figure 7 shows the optimal scheduling results for PFC in TSS 3 in stages 2 and 3. It can be seen that the power profile of PFC's convertors became smoother after optimizing $\Phi_{3}$. Also, the positive value for the $\alpha$-phase convertor and the negative value for the $\beta$-phase convertor show that the power is injected into DC bus of PFC. Besides, the renewable resources and ESS participated effectively in managing the power flow in each TSS to achieve its desired goals. Also, through utilizing PTC units, TSSs can exchange power to supply their demand and reduce their dependency on the external grid. Figure 8 shows the transferred power between TSS 3 and 2, and Figure 9 shows the exchanged power between TSS 3 and the upstream grid.

Figure 10 shows the state of charge (SOC) of ESSs. As mentioned earlier, the charging and discharging power of ESS decreased after minimizing $\Phi 2$ in the second stage. As a consequence of improving the independence of CCTPS, the use of ESSs has decreased, so that the total daily charging or discharging them has reduced from about $4.838 \mathrm{MWh}$ to $4.800 \mathrm{MWh}$ or $0.6 \%$, while the daily operation cost is constant. It can be concluded that the operating cost of ESSs is improved. Also, the average of total stored energy in TSSs decreased by $730 \mathrm{kWh}$ or $2.8 \%$, comparing the results of the first and second stages.

\section{Conclusion}

The planning and operation of electric railway systems is an evolving field. A flexible traction power supply system integrating back-to-back converters, storage systems, and renewable energies will be a key component of the smart railway systems. This study proposes a multistage multiobjective optimal energy management strategy for an interconnected traction power system, in which along with the upstream power grid, renewable energies, such as solar and wind power, are used to supply the traction power demand. Minimizing the daily operating cost, the dependency on the upstream grid, and the three-phase voltage unbalance ratio have been considered as the objectives of the proposed model utilizing mixed-integer quadratically constrained programming. The obtained results have been compared to similar available studies to show the merits of the proposed model. Also, simulation results approve that the system independence and generating the voltage unbalance could be effectively managed by the proposed energy management strategy without any additional cost. Specifically, CCTPS independency and its three-phase voltage unbalance ratio have been improved by about $12 \%$ and $15 \%$, respectively. Developing the model as a bilevel optimization problem is considered for the future study.

\section{Acronyms}

CCTPS: Connected cophase traction power system

ESS: Energy storage system

ERS: Electrical railway system

MILP: Mixed-integer linear programming

MIQCP: Mixed-integer quadratically constrained programming

NLP: Nonlinear programming

PF: $\quad$ Power factor

PFC: $\quad$ Power flow controller

PTC: $\quad$ Power transfer controller

PQ: $\quad$ Power quality

RBE: Regenerative braking energy

RER: Renewable energy resource

RTP: Real-time pricing

SOC: $\quad$ State of charge

SOE: $\quad$ State of energy

TSS: Traction substation

VUR: Voltage unbalanced ratio.

\section{Indices and sets}

I: $\quad$ Set of TSSs

T: $\quad$ Set of time intervals

$t$ : Index of time interval

$i$ and $j$ : Index of TSS.

\section{Parameters}

$\delta_{i}^{b}$ : $\quad$ Self-discharging rate of ESS

$\eta_{i}^{b, c}, \eta_{i}^{b, d}: \quad$ Charging/discharging efficiency of ESS

$E_{i}^{\max }, E_{i}^{\mathrm{min}}:$ Minimum and maximum allowed SOE limit of ESS

$P_{i}^{\max , c}, \quad$ Maximum charging/discharging rate of ESS

$P_{i}^{\max , d}$ :

$P_{i, t}^{p v}:$

$\eta_{i}^{p v}:$

$S_{i}^{p v}:$

$I_{i, t}^{p v}$ :

$T_{i, t}^{a, a}:$

$P_{i, t}^{W}$ :

Generated power from PV at time interval $t$

Conversion coefficient of solar unit (\%)

Array area of solar unit

Solar irradiance $\left(\mathrm{kW} / \mathrm{m}^{2}\right)$

Ambient temperature at time interval $t$

Generated power from wind turbines at time interval $t$

$V_{i, t}: \quad$ Wind speed at time interval $t$

$v_{i}^{c,}, v_{i}^{r}$, and The cut-in, rated, and cut-out wind speeds

$v_{i}^{c o}$ :

$A_{i}, B_{i}$, and Wind turbine constants

$C_{i}$ :

$P_{i}^{W, N o m}: \quad$ The rated output power of wind turbine 


\begin{tabular}{|c|c|}
\hline $\begin{array}{l}S_{i, j}^{P T C}: \\
S_{i}^{\alpha}, S_{i}^{\beta}:\end{array}$ & $\begin{array}{l}\text { The capacity of PTC between TSS } i \text { and } j \\
\text { The capacity of the } \alpha \text { and } \beta \text {-phase converters of } \\
\text { PFC in the } i^{\text {th }} \text { TSS }\end{array}$ \\
\hline${ }_{t}, Q_{i, t}^{L}:$ & $\begin{array}{l}\text { The active and reactive power of traction load } \\
\text { at time interval } t\end{array}$ \\
\hline & $\begin{array}{l}\text { The active and reactive power of regenerative } \\
\text { braking at time interval } t\end{array}$ \\
\hline${ }^{l y}, \rho_{t}^{\text {sell }}:$ & $\begin{array}{l}\text { Price of purchasing/selling power from/to the } \\
\text { main grid at time interval } t\end{array}$ \\
\hline & The rated line-to-line voltage of the grid \\
\hline & $\begin{array}{l}\text { The voltage of the single-phase traction } \\
\text { transformer in the traction side }\end{array}$ \\
\hline & $\begin{array}{l}\text { The input voltage of the } \alpha \text {-phase converter in } \\
\text { the grid side }\end{array}$ \\
\hline & The negative current in the grid side \\
\hline & The short-circuit capacity \\
\hline & $\begin{array}{l}\text { The upper limit of three-phase voltage } \\
\text { unbalanced ratio }\end{array}$ \\
\hline & $\begin{array}{l}\text { The binary parameters for PTC between TSS } i \\
\text { and } j \text {, indicating the status of transferring } \\
\text { power. }\end{array}$ \\
\hline
\end{tabular}

\section{Variables}

$E_{i, t}^{b}: \quad$ Energy stored in ESS of the $i^{\text {th }}$ TSS at time

interval $t$

$P_{i, t}^{b, d}, P_{i, t}^{b, c}$ : Power charging/discharging rate of ESS at time interval $t$

$u_{i, t}^{b, c}, u_{i, t}^{b, d}: \quad$ Binary variable for ESS charging/discharging constraint

$u_{i, t}^{\text {linear }}$ : Binary auxiliary variable for linearization

$P_{i, j, t}^{P T C}, \quad$ The active and reactive transferred power

$Q_{i, j, t}^{P T C}: \quad$ between TSS $i$ and $j$ through PTC

$P_{i, t}^{\alpha}: \quad$ The power of the $\alpha$-phase converter of PFC in the $i^{\text {th }}$ TSS at time interval $t$

$P_{i, t}^{\beta}, Q_{i, t}^{\beta}$ : The active and reactive power of the $\beta$-phase converter of the PFC in the $i^{\text {th }}$ TSS at time interval $t$

$P_{i, t}^{G, \text { buy }}$ : Purchased power from the external grid

$P_{i, t}^{G, \text { sell }}$ : $\quad$ Sold power to the external grid

$P_{i, t}^{S T}: \quad$ The power of the single-phase traction transformer at time interval $t$

$\varepsilon_{i, t}^{U}: \quad$ The voltage unbalanced ratio.

\section{Data Availability}

All data, models, or codes that support the findings of this study are available from the corresponding author upon request.

\section{Conflicts of Interest}

The authors declare that they have no conflicts of interest.

\section{References}

[1] L. Bilgili, S. L. Kuzu, A. Y. Çetinkaya, and P. Kumar, "Evaluation of railway versus highway emissions using LCA approach between the two cities of Middle Anatolia," Sustainable Cities and Society, vol. 49, Article ID 101635, 2019.

[2] X. Tian, X. Sun, N. Lu, and J. Song, "A new scheme to identify the special load current waveform for a Metro DC traction system," International Transactions on Electrical Energy Systems, vol. 31, no. 2, pp. 1-19, 2021.

[3] L. Perera, R. G. Thompson, and W. Wu, "A multi-class tollbased approach to reduce total emissions on roads for sustainable urban transportation," Sustainable Cities and Society, vol. 63, Article ID 102435, 2020.

[4] M. Liu, S. Jia, P. Li, X. Liu, and Y. Zhang, "Predicting GHG emissions from subway lines in the planning stage on a city level," Journal of Cleaner Production, vol. 259, Article ID 120823, 2020.

[5] Z. Zhong, Y. Zhang, H. Shen, and X. Li, "Optimal planning of distributed photovoltaic generation for the traction power supply system of high-speed railway," Journal of Cleaner Production, vol. 263, Article ID 121394, 2020.

[6] D. Serrano-Jiménez, L. Abrahamsson, S. Castaño-Solís, and J. Sanz-Feito, "Electrical railway power supply systems: current situation and future trends," International Journal of Electrical Power \& Energy Systems, vol. 92, pp. 181-192, 2017.

[7] P. Arboleya, C. Mayet, B. Mohamed, J. A. Aguado, and S. d. 1. Torre, "A review of railway feeding infrastructures: mathematical models for planning and operation," eTransportation, vol. 5, Article ID 100063, 2020.

[8] S. Khayyam, F. Ponci, J. Goikoetxea, V. Recagno, V. Bagliano, and A. Monti, "Railway energy management system: centralized-decentralized automation architecture," IEEE Transactions on Smart Grid, vol. 7, no. 2, pp. 1164-1175, 2016.

[9] Y. Ying, Q. Liu, M. Wu, and Y. Zhai, "The flexible smart traction power supply system and its hierarchical energy management strategy," IEEE Access, vol. 9, pp. 64127-64141, 2021.

[10] G. Cui, L. Luo, C. Liang et al., "Supercapacitor integrated railway static power conditioner for regenerative braking energy recycling and power quality improvement of highspeed railway system," IEEE Transactions on Transportation Electrification, vol. 5, no. 3, pp. 702-714, 2019.

[11] L. Jiang, Z. Bie, T. Long, H. Xie, and Y. Xiao, "Distributed energy management of integrated electricity-thermal systems for high-speed railway traction grids and stations," CSEE Journal of Power and Energy Systems, vol. 7, no. 3, pp. 541-554, 2020.

[12] Y. Liu, M. Chen, S. Lu, Y. Chen, and Q. Li, “Optimized sizing and scheduling of hybrid energy storage systems for highspeed railway traction substations," Energies, vol. 11, no. 9, Article ID 2199, 2018.

[13] P. Cheng, H. Kong, J. Ma, and L. Jia, "Evolution toward resilient traction power supply systems of railways with interconnected microgrids," CSEE Journal of Power and Energy Systems, vol. 7, no. 5, pp. 1122-1132, 2020.

[14] L. Razik, N. Berr, S. Khayyam, F. Ponci, and A. Monti, "REMS-Railway energy management in real rail operation," IEEE Transactions on Vehicular Technology, vol. 68, no. 2, pp. 1266-1277, 2019.

[15] L. Li and M. Wu, "A three-phase symmetric converter in AC electric railway systems for power quality and energy efficient improvement," International Transactions on Electrical Energy Systems, vol. 31, no. 9, pp. 1-33, 2020.

[16] Y. Zhou, A. Zhang, H. Zhang, J. Huang, W. Yang, and L. Zhang, "Proportional integral resonance based sliding mode control of VIENNA rectifier for charging station of tramcar under unbalanced power supply," International 
Transactions on Electrical Energy Systems, vol. 30, no. 10, pp. 1-18, 2020.

[17] Y. Wang, Z. Liu, X. Mu, X. Song, K. Huang, and Y. Deng, "Research on electromagnetic transient process in articulated split-phase insulator of high-speed railway considering viaduct's electrical coupling," International Transactions on Electrical Energy Systems, vol. 27, no. 10, pp. e2376-19, 2017.

[18] H. J. Kaleybar, S. S. Fazel, A. R. Vayghan, M. Brenna, and F. Foiadelli, "Performance improvement of railway power conditioner with model predictive control approach," in Proceedings of the 2019 IEEE Milan PowerTech, pp. 1-6, Milan, Italy, June 2019.

[19] Z. Shu, S. Xie, and Q. Li, "Single-phase back-to-back converter for active power balancing, reactive power compensation, and harmonic filtering in traction power system," IEEE Transactions on Power Electronics, vol. 26, no. 2, pp. 334-343, 2011.

[20] N. Y. Dai, M. C. Wong, K. W. Lao, and C. K. Wong, "Modelling and control of a railway power conditioner in cophase traction power system under partial compensation," IET Power Electronics, vol. 7, no. 5, pp. 1044-1054, 2014.

[21] F. Ma, Q. Xu, Z. He et al., "A railway traction power conditioner using modular multilevel converter and its control strategy for high-speed railway system," IEEE Transactions on Transportation Electrification, vol. 2, no. 1, pp. 96-109, 2016.

[22] X. He, Z. Shu, X. Peng et al., "Advanced cophase traction power supply system based on three-phase to single-phase converter," IEEE Transactions on Power Electronics, vol. 29, no. 10, pp. 5323-5333, 2014.

[23] M. Chen, Q. Li, C. Roberts et al., "Modelling and performance analysis of advanced combined co-phase traction power supply system in electrified railway," IET Generation, Transmission \& Distribution, vol. 10, no. 4, pp. 906-916, 2016.

[24] N. Y. Dai, C. K. Wong, M. C. Wong, and K. W. Lao, "Hybrid power quality conditioner for co-phase power supply system in electrified railway," IET Power Electronics, vol. 5, no. 7, pp. 1084-1094, 2012.

[25] M. Minwu Chen, J. Jie Luo, W. Wenbing Jiang, and Y. Yaowu Wang, "Study on new traction power supply system for power quality comprehensive compensation in electrified railway," in Proceedings of the TENCON 2015-2015 IEEE Region 10 Conference, Macao, November 2016.

[26] Z. Shu, S. Xie, K. Lu et al., "Digital detection, control, and distribution system for co-phase traction power supply application," IEEE Transactions on Industrial Electronics, vol. 60, no. 5, pp. 1831-1839, 2013.

[27] Q. Li, "New generation traction power supply system and its key technologies for electrified railways," Journal of Modern Transportation, vol. 23, no. 1, pp. 1-11, 2015.

[28] Z. H. Tan, K. H. Chua, Y. S. Lim, S. Morris, L. Wang, and J. H. Tang, "Optimal operations of transformers in railway systems with different transformer operation modes and different headway intervals," International Journal of Electrical Power \& Energy Systems, vol. 127, Article ID 106631, 2021.

[29] S. Akbari, S. S. Fazel, and S. Jadid, "Optimal operation of a smart railway station based on a multi-energy hub structure considering environmental perspective and regenerative braking utilization," Energy Science \& Engineering, vol. 9, no. 9, pp. 1614-1631, 2021.

[30] Y. Li, R. Tian, M. Wei et al., “An improved operation strategy for CCHP system based on high-speed railways station case study," Energy Conversion and Management, vol. 216, Article ID $112936,2020$.
[31] S. Akbari, S. S. Fazel, and S. Jadid, "Optimal coordinated operation of integrated energy hubs, considering regenerative braking utilization," IET Electrical Systems in Transportation, vol. 11, no. 4, pp. 362-376, 2021.

[32] X. Liu and K. Li, "Energy storage devices in electrified railway systems: a review," Transportation Safety and Environment, vol. 2, no. 3, pp. 183-201, 2020.

[33] A. Ovalle, J. Pouget, S. Bacha, L. Gerbaud, E. Vinot, and B. Sonier, "Energy storage sizing methodology for masstransit direct-current wayside support: application to French railway company case study," Applied Energy, vol. 230, pp. 1673-1684, 2018.

[34] C. Huang, Y. Xie, Y. Liu, and M. Chen, "Energy management of Co-phase traction power supply system considering PV and hybrid energy access based on information gap decision theory," in Proceedings of the 2020 IEEE Sustainable Power and Energy Conference (iSPEC), pp. 238-244, Chengdu, China, November 2020.

[35] J. A. Aguado, A. J. Sanchez Racero, and S. De La Torre, "Optimal operation of electric railways with renewable energy and electric storage systems," IEEE Transactions on Smart Grid, vol. 9, no. 2, pp. 993-1001, 2018.

[36] S. R. Salkuti, "Optimal operation of electrified railways with renewable sources and storage," Journal of Electrical Engineering and Technology, vol. 16, no. 1, pp. 239-248, 2021.

[37] C. Sumpavakup, T. Ratniyomchai, and T. Kulworawanichpong, "Optimal energy saving in DC railway system with on-board energy storage system by using peak demand cutting strategy," Journal of Modern Transportation, vol. 25, no. 4, pp. 223-235, 2017.

[38] S. Khayyam, N. Berr, L. Razik, M. Fleck, F. Ponci, and A. Monti, "Railway system energy management optimization demonstrated at offline and online case studies," IEEE Transactions on Intelligent Transportation Systems, vol. 19, no. 11, pp. 3570-3583, 2018.

[39] M. Chen, Z. Cheng, Y. Liu, Y. Cheng, and Z. Tian, "Multitimescale optimal dispatch of railway FTPSS based on model predictive control," IEEE Transactions on Transportation Electrification, vol. 6, no. 2, pp. 808-820, 2020.

[40] Y. Liu, M. Chen, Y. Chen, and L. Chen, "Energy management of connected co-phase traction power system considering HESS and PV," in Proceedings of the 2019 14th IEEE Conference on Industrial Electronics and Applications (ICIEA) 2019, pp. 1408-1412, Xi'an, China, June 2019.

[41] Y. Liu, M. Chen, Z. Cheng, Y. Chen, and Q. Li, "Robust energy management of high-speed railway Co-phase traction substation with uncertain PV generation and traction load," IEEE Transactions on Intelligent Transportation Systems, vol. 99, pp. 1-13, 2021.

[42] K. Saberi, H. Pashaei-Didani, R. Nourollahi, K. Zare, and S. Nojavan, "Optimal performance of CCHP based microgrid considering environmental issue in the presence of real time demand response," Sustainable Cities and Society, vol. 45, pp. 596-606, 2019.

[43] M. Babaei, E. Azizi, M. T. Beheshti, and M. Hadian, "DataDriven load management of stand-alone residential buildings including renewable resources, energy storage system, and electric vehicle," Journal of Energy Storage, vol. 28, Article ID 101221, 2020.

[44] M. A. Mirzaei, M. Nazari-Heris, K. Zare et al., "Evaluating the impact of multi-carrier energy storage systems in optimal operation of integrated electricity, gas and district heating networks," Applied Thermal Engineering, vol. 176, Article ID 115413, 2020. 
[45] D. T. Nguyen and L. B. Le, "Optimal bidding strategy for microgrids considering renewable energy and building thermal dynamics," IEEE Transactions on Smart Grid, vol. 5, no. 4, pp. 1608-1620, 2014.

[46] E. Skoplaki and J. A. Palyvos, "On the temperature dependence of photovoltaic module electrical performance: a review of efficiency/power correlations," Solar Energy, vol. 83, no. 5, pp. 614-624, 2009.

[47] M. Power: Technical Drawings SOLAR CELLS POLYCRYSTALLINE $156 \times 156 \mathrm{MM} 72$ PCS. $(6 \times 12)-4$ BUS BARS, 2020, http://sunceco.com/wp-content/uploads/2017/01/ SEP300-320.pdf.

[48] H. Siahkali and M. Vakilian, "Stochastic unit commitment of wind farms integrated in power system," Electric Power Systems Research, vol. 80, no. 9, pp. 1006-1017, 2010.

[49] Y. Chen, M. Chen, Z. Tian, and Y. Liu, "Voltage unbalance management for high-speed railway considering the impact of large scale DFIG-based wind farm," IEEE Transactions on Power Delivery, vol. 35, no. 4, pp. 1667-1677, 2020.

[50] Y. Cui, Z. Geng, Q. Zhu, and Y. Han, "Review: multi-objective optimization methods and application in energy saving," Energy, vol. 125, pp. 681-704, 2017.

[51] Gams: CPLEX 12 Solver Description, 2020, https://www. gams.com/33/docs/S_CPLEX.htmlReffrence 51 is an internet site: https://www.gams.com/33/docs/S_CPLEX.html. 